\title{
Development of a counterselectable seamless mutagenesis system in lactic acid bacteria
}

\author{
Yongping Xin, Tingting Guo, Yingli Mu and Jian Kong* (i)
}

\begin{abstract}
Background: Lactic acid bacteria $(L A B)$ are receiving more attention to act as cell factories for the production of high-value metabolites. However, the molecular tools for genetic modifying these strains are mainly vector-based double-crossover strategies, which are laborious and inefficient. To address this problem, several counterselectable markers have been developed, while few of them could be used in the wild-type host cells without pretreatment.

Results: The pheS gene encoding phenylalanyl-tRNA synthetase alpha subunit was identified in Lactococcus lactis NZ9000 genome. When mutant pheS gene (pheS*) under the control of the Lc. lactis NZ9000 L-lactate dehydrogenase promoter $\left(\mathrm{P}_{\text {Idh }}\right)$ was expressed from a plasmid, the resulted PheS* with an A312G substitution rendered cells sensitive to the phenylalanine analog $p$-chloro-phenylalanine ( $p$-Cl-Phe). This result suggested $p h S^{*}{ }^{*}$ was suitable to be used as a counterselectable marker in Lc. lactis. However, the expression level of pheS* from a chromosomal copy was too low to confer $p$-Cl-Phe sensitivity. Therefore, a strategy of cascading promoters was attempted for strengthening the expression level of pheS* Expectedly, a cassette 5Pldh-pheS* with five tandem repetitive promoters $P_{1 d h}$ resulted in a sensitivity to $15 \mathrm{mM} \mathrm{p}$-Cl-Phe. Subsequently, a counterselectable seamless mutagenesis system PheS*/pG ${ }^{+}$host9 based on a temperature-sensitive plasmid $\mathrm{pG}^{+}$host9 harboring a 5PIdh-pheS* cassette was developed in Lc. lactis. We also demonstrated the possibility of applying pheS* to be a counterselectable marker in Lactobacillus casei BL23.
\end{abstract}

Conclusions: As reported in E. coli, pheS* as a counterselectable marker has been demonstrated to be functional in targeted gene(s) deletion in Lc. lactis as well as in L. casei. Moreover, the efficiency and timesaving counterselectable seamless mutagenesis system PheS*/pG ${ }^{+}$host9 could be used in the wild-type host cells without pretreatment.

Keywords: Lactic acid bacteria, Temperature-sensitive plasmid, Seamless mutagenesis, Counterselectable marker, phes

\section{Background}

Lactic acid bacteria (LAB) are important microorganisms used as starter cultures in the dairy fermented processes $[1,2]$. Due to their generally recognized as safe status, some LAB strains have been used as cell factories or vaccine delivery vehicles for the heterogeneous production of specific compounds [3, 4] or pharmaceutical molecules [5-8]. Also, since the wealth of genomic data being delivered by massively parallel sequencing, interests in

*Correspondence: kongjian@sdu.edu.cn

State Key Laboratory of Microbial Technology, Shandong University, 27

Shanda Nanlu, Jinan 250100, People's Republic of China development of high-efficiency genome engineering tools for rerouting natural metabolic pathways to produce high valuable end products were increasing $[9,10]$. Considering of the importance of the recombineering system in $L A B$, significant efforts have been recently concentrated on the exploitation of gene targeting techniques in $\mathrm{LAB}$ to accelerate genome engineering or gene functional analysis, as the recently reported single-stranded DNA recombineering (SSDR) system and double-stranded DNA recombineering (DSDR) system [11-13].

The SSDR system was established in Lactobacillus reuteri and Lactococcus lactis and could generate precision genome mutations without leaving any other foreign 
DNA [11]. The major limitation is the ability to achieve efficiencies that would allow the modification of any sites in the genome and easily recover the mutants without selection [14]. To address this problem, enhanced SSDR has been achieved with the assistant of the typeII clustered regularly interspaced short palindromic repeats locus from Streptococcus pyogenes in L. reuteri and $>99.99 \%$ of non-recombinants could be eliminated without antibiotic selection [12]. But it could not be used for gene(s) deletion or insertion in other LAB because it has not proved the functional application of type-II CRISPR-Cas system in LAB except for L. reuteri. The DSDR technique was established in L. plantarum which was involved in the efficiently generation of gene(s) deletion or insertion [13]. However, this genetic system was not functional in other $\mathrm{LAB}$ and still left a lox72 site, a heterologous DNA sequence after the antibiotic selection marker excised from the genome.

Seamless mutagenesis refers to targeted mutagenesis without any other micro-change, such as the presence of the selectable marker used to screen mutants or a loxP site after excising the selectable marker [15]. The seamless mutagenesis strategy usually appropriate for mutating the protein coding region in which any extraneous sequence introduced could interfere with protein expression. So far, several seamless mutagenesis methods based on homologous double-crossover have been successfully achieved in LAB, but the most widely used seamless mutagenesis strategy was based on a temperature-sensitive plasmid such as $\mathrm{pG}^{+}$host9 [16] or $\mathrm{pG}^{+}$host5 [17]. The merit of these plasmids is that both the non-replicate temperature at $37{ }^{\circ} \mathrm{C}$ and the replicate temperature at $28{ }^{\circ} \mathrm{C}$ are the adaptive temperature for the growth of most LAB. With plasmid $\mathrm{pG}^{+}$host9 [16], several chromosomal deletion derivatives of Lc. lactis and Streptococcus thermophilus were obtained in our laboratory [18-20]. However, these vectors, while powerful, suffer from a relatively low rate of recombination events and require labor-intensive screening procedures to distinguish clones with the desired seamless mutants. Therefore, improving the efficiency of this seamless mutagenesis system for fast analysis the function of gene(s) in LAB is very instant.

In recent years, a two-step selection/counterselection strategy has been demonstrated to be functional in improving the efficiency of method for fast generating seamless mutagenesis in the genome, which is normally consist of a positive selectable marker (usually an antibiotic resistance gene) and a counterselectable cassette. Counterselectable markers, including the genes upp [21-23] and oroP [24], have been characterized and functionally analyzed. However, the counterselectable marker upp could not be made in wild-type LAB strains without pre-treatment while oroP has not been widely used for other LAB strains [21-24].

Recently, gene pheS encoding phenylalanyl-tRNA synthetase alpha subunit has been demonstrated to function as a host strain-independent counterselectable marker in Thermus thermophilus, Bacteroides sp., Escherichia coli and Streptococcus mutans [25-28], but has yet not been used in the model strain Lc. lactis. In E. coli, only an A294G substitution in the protein PheS altered the specificity of the phenylalanyl-tRNA synthetase which resulted in the sensitivity to phenylalanine analogs such as $p$-chloro-phenylalanine ( $p$-Cl-Phe) [27]. In this study, we identified a conserved alanine residue in the PheS protein, and demonstrated that the dominant-negative mutant protein PheS* with an A312G amino acid substitution rendered cells sensitive to $15 \mathrm{mM} p$-Cl-Phe in $L c$. lactis NZ9000 and $10 \mathrm{mM} p$-Cl-Phe in L. casei BL23. To employ this conditional lethal gene $p h S^{*}$ as a negative selectable marker, a high-efficiency seamless mutagenesis system $\mathrm{PheS}^{*} / \mathrm{pG}^{+}$host9 based on a temperature-sensitive plasmid $\mathrm{pG}^{+}$host 9 carrying a $5 \mathrm{P}_{\text {ldh }}$-pheS ${ }^{*}$ cassette was constructed in Lc. lactis NZ9000. The aim of this study is to explore the potential of using $p h e S^{*}$ as a counterselectable marker for rapidly screening mutants for targeted gene analysis or genome engineering in LAB.

\section{Methods}

\section{Plasmids, bacterial strains, and growth conditions}

The plasmids and bacterial strains used in this study are shown in Table 1. E. coli DH5 $\alpha$ was used as the host for cloning procedures and grown aerobically in Luria-Ber$\operatorname{tani}(\mathrm{LB})$ medium at $37^{\circ} \mathrm{C}$. Unless otherwise specified, Lc. lactis and $L$. casei were grown statically at $30{ }^{\circ} \mathrm{C}$ in M17 (Oxoid) broth supplemented with $0.5 \%$ glucose (GM17) and at $37{ }^{\circ} \mathrm{C}$ in MRS (Oxiod) broth, respectively. For counterselection, semi-defined M9 plates [29] supplemented with $0.4 \%$ glucose, namely GM9 plates, were added with $15 \mathrm{mM} p$-Cl-Phe (Sigma) for Lc. lactis and $10 \mathrm{mM} p$-Cl-Phe (Sigma) for L. casei. If required, antibiotics were added as follows: $10 \mu \mathrm{g} / \mathrm{ml}$ erythromycin or $5 \mu \mathrm{g} / \mathrm{ml}$ chloramphenicol for Lc. lactis, $5 \mu \mathrm{g} / \mathrm{ml}$ erythromycin for $L$. casei, $10 \mu \mathrm{g} / \mathrm{ml}$ chloramphenicol, $100 \mu \mathrm{g} / \mathrm{ml}$ ampicillin and $300 \mu \mathrm{g} / \mathrm{ml}$ erythromycin for $E$. coli DH5 $\alpha$.

\section{Reagents and enzymes}

All enzymes used in this study were purchased from TaKaRa. Restriction enzymes and T4 DNA ligases were used according to standard procedures. PCR amplicons for cloning purposes were generated by $2 \times$ PrimeSTAR max premix, and PCR reactions for screening purposes were performed with rTaq DNA polymerase. All oligonucleotides used in this study are listed in Table 2. 
Table 1 Plasmids and bacterial strains used in this study

\begin{tabular}{|c|c|c|}
\hline Strain or plasmid & Characteristic(s) & Source \\
\hline \multicolumn{3}{|l|}{ Strains } \\
\hline Escherichia coli DH5a & $\mathrm{F}^{-}$supE44 $\triangle \mathrm{acU} 169$ Ф80/acZ $\mathrm{M} 15$ hsdR17 recA1 endA1 gyrA96 thi-1 relA1 & Novagen \\
\hline \multicolumn{3}{|l|}{ Lactococcus lactis strains } \\
\hline NZ9000 & Derivative of MG1363, pepN::nisRK & {$[33]$} \\
\hline IGn & Derivative of NZ9000, galK::pG+UD-nP-pheS* & This work \\
\hline$d A$ & Derivative of NZ9000, $\triangle a l d B$ & This work \\
\hline Lactobacillus casei BL23 & Derivative of L. casei ATCC 393 (pLZ15) & {$[36]$} \\
\hline \multicolumn{3}{|l|}{ Plasmids } \\
\hline $\mathrm{pG}^{+}$host9 & Ermr; temperature-sensitive vector & {$[16]$} \\
\hline $\mathrm{pG}+\mathrm{UD}$ & $\mathrm{pG}^{+}$host9 derivative with up and down homology arms of the part of galactose operon & This work \\
\hline pG ${ }^{+} U D-n P-p h e S^{*}$ & $\mathrm{pG}^{+} \mathrm{UD}$ derivative with pheS* driven by $n \mathrm{P}_{\text {ldh }}$ & This work \\
\hline $\mathrm{pG}^{+}-\mathrm{nP}-\mathrm{pheS}^{*}$ & $\mathrm{pG}^{+}$host9 derivative with pheS* driven by $n \mathrm{P}_{\mathrm{Idh}}$ & This work \\
\hline $\mathrm{pG}^{+} \mathrm{UD2}-5 \mathrm{P}-\mathrm{pheS}{ }^{*}$ & $\mathrm{pG}^{+}-5 \mathrm{P}$-pheS* derivative with upstream and downstream sequences of the aldB gene & This work \\
\hline pUC19 & Ampr; cloing vector & This work \\
\hline pSec:Leiss:Nuc & pWV01 replicon; expresses Nuc under PnisA control; $\mathrm{Cm}^{r}$ & {$[34]$} \\
\hline pleiss-P-pheS* & pSec:Leiss:Nuc derivative with pheS* driven by a $\mathrm{P}_{\text {Idh }}$ & This work \\
\hline pTRKH2 & Erm?; expressing vector & {$[37]$} \\
\hline pOgfp & Source of gfp gene & {$[18]$} \\
\hline
\end{tabular}

\section{Bioinformatic analysis}

A multiple-sequence alignment was performed using Clustal X, version 2.0 [30] and ESPript 3.0 [31]. The amino acid sequences of PheS proteins from six LAB strains were aligned with the amino acid sequences of PheS proteins from E. coli [27] and E. faecalis [32].

\section{Construction of the counterselectable system PheS*/ pG ${ }^{+}$host9 in Lc. lactis}

The counterselectable $\mathrm{P}_{\mathrm{ldh}}$-pheS* cassette was constructed using an overlap extension PCR strategy. The constitutive promoter region of the L-lactate dehydrogenase gene (ldh) (accession number: NC_017949) in Lc. lactis NZ9000 [33] was amplified by PCR using primer pair ldhF1 and ldhR1. The pheS* gene was generated as two fragments by PCR using the Lc. lactis NZ9000 chromosomal DNA as a template with the primer pairs pheSF and siteR, siteF and pheSR, respectively. The point mutation responsible for $p$-Cl-Phe sensitivity was introduced by the primers siteF and siteR annealing internal to the wild-type pheS gene. There are overlapping regions among the three amplicons, which allowed an overlap extension PCR step using primers ldhF1 and pheSR to create $\mathrm{P}_{\text {ldh }}$-pheS* cassette. The generated $1270 \mathrm{bp}$ $\mathrm{P}_{\text {ldh-pheS* }}$ cassette was digested with EcoRI and BglII and ligated to the compatible sites of Lc. lactis/E. coli shuttle vector pSec:Leiss:Nuc [34], creating pleiss-P-pheS*.

To investigate the feasibility of the counterselectable $\mathrm{P}_{\text {ldh }}-$ pheS* cassette, the plasmid pleiss-P-pheS* was introduced into the competent cells of Lc. lactis NZ9000 by electroporation [35]. The recombinant strain Lc. lactis NZ9000/pleiss-P-pheS* was incubated in GM17 with $5 \mu \mathrm{g} / \mathrm{ml}$ chloramphenicol. Overnight cultures were tenfold serially diluted, and $5 \mu \mathrm{l}$ of diluted solution were pipetted onto air dried GM9 plates containing $0,5,10$, $15 \mathrm{mM} p$-Cl-Phe, the cell survival was measured.

\section{Construction of plasmids pleiss-nP-gfp}

To demonstrate whether cascading promoters could increase the $g f p$ gene expression, a series of plasmids pleiss-nP-gfp carrying promoter clusters $\mathrm{nP}_{1 \mathrm{dh}}-g f p$ were constructed as follows: the $g f p$ gene was PCR amplified using primers gfpF and gfpR from plasmid pOgfp [18]. the promoter $\mathrm{P}_{\mathrm{ldh}}$ and $g f p$ gene were fused by an overlap extension PCR using primers ldhF2 and gfpR. The resulting product $\mathrm{P}_{\mathrm{ldh}}-g f p$ was digested with $B g l \mathrm{II}$ and EcoRI and ligated into the corresponding sites of pSec:Leiss:Nuc [34] to create plasmid pleiss-P-gfp. The promoter $\mathrm{P}_{\mathrm{ldh}}$ was generated by PCR with primers ldhF2 and ldhR2, and the PCR product was digested with $B g l \mathrm{II}$ and $B a m \mathrm{HI}$ and inserted into the BglII site of pleiss-P-gfp to generate pleiss-2P-gfp. The same procedure was carried out to construct the plasmid pleiss-nP-gfp ( $\mathrm{n}$ : the copy number of $\mathrm{P}_{\mathrm{ldh}}$ in the promoter clusters $\mathrm{nP}_{\mathrm{ldh}}-g f p$ ). Then, the above plasmids pleiss-nP-gfp were introduced into Lc. lactis NZ9000.

\section{Fluorescence assay}

Recombinant strains harboring the pleiss-nP-gfp were grown aerobically in $5 \mathrm{ml}$ GM17 broth containing $5 \mu \mathrm{g}$ / 
Table 2 Oligonucleotide primers used in this study

\begin{tabular}{|c|c|c|}
\hline Primer & Sequence $\left(5^{\prime}-3^{\prime}\right)^{a}$ & Restriction site \\
\hline aldB-uF & AGGGTACCGGCGAAAGTCATGTAACAATCC & Kpnl \\
\hline aldB-uR & CTGACATGATATTTCTCTTTTCTAT & \\
\hline aldB-dR & CCGCTCGAGTGCTGACAGATGGCTGGCTGTG & Xhol \\
\hline aldB-dF & GAAAAGAGAAATATCATGTCAGTAATTGCTTAAATTTCTTTAGC & \\
\hline aldB-testF & ATATTTCTGCCACAATTTTCATGCC & \\
\hline aldB-testR & CCAATCCTGTACCAATAACAGCAAT & \\
\hline pheSF & ATAAAAAATCGAAAAGGAGATAAAAATGAACTTACAAGAAAAAATTGAAG & \\
\hline pheSR & AAAGATCTTCAGTCGAATTGTTCTAAGAATC & $B g / l l$ \\
\hline pheSR2 & AAGAATTCTCAGTCGAATTGTTCTAAGAATC & ECoRl \\
\hline siteR & ACCAAAACCAGAATAAACAGAAG & \\
\hline siteF & CTGTTTATTCTGGTTTTGGTTTTGGACTCGGTCAAGAACG & \\
\hline IdhF1 & CCGAATTCATTCATTTTACACATTGTA & EcoRl \\
\hline IdhF2 & GACAGATCTATTCATTTTACACATTGTA & Bg/ll \\
\hline IdhF3 & AGACGTCGACATTCATTTTACACATTGTA & Sall \\
\hline IdhR1 & TTTTATCTCCTTTTCGATTTTTTAT & \\
\hline IdhR2 & CGGGATCCTTTTATCTCCTTTTCGATTTTTTTAT & $\mathrm{BamHI}$ \\
\hline IdhR3 & CCGCTCGAGTTTTATCTCCTTTTCGATTTTTTAT & Xhol \\
\hline upF & AGGGTACCATGTCAATAGTTGTCGAAAA & Kpnl \\
\hline upR & CAGTTTCTGCTAAGGTATCA & \\
\hline downF & TGATACCTTAGCAGAAACTGATGAATTAGCACAGCAAGTG & \\
\hline downR & CCGCTCGAGCTCTAGTAAAATGTTCCTCA & Xhol \\
\hline testF & TTAAGGAAATGAATTTAGAGGAGAG & \\
\hline testR & AAACCTTCATGTCCTTCTTGAGT & \\
\hline BL-pheSF & AAAGATCTATGGATCTTCAAACCAAACTTG & $B g / l l$ \\
\hline BL-siteR & ACCAAAACCGCCGTAAACGTC & \\
\hline BL-siteF & GACGTTTACGGCGGTTTTGGTTTTGGCCTTGGTCCTGATCG & \\
\hline BL-pheSR & GATCTGCAGTTAACCCTCCTGGCTGAATTGC & Pstl \\
\hline gfpF & ATAAAAAATCGAAAAGGAGATAAAAAGATATGAGCAAAGGAG & \\
\hline gfpR & CGCGAATTCTTAGTAGAGCTCATC & EcoRl \\
\hline
\end{tabular}

a The restriction sites in the primer sequences are underlined

ml chloramphenicol at $30{ }^{\circ} \mathrm{C}$. Samples for measurement were taken out after $12 \mathrm{~h}$ and harvested by centrifugation at $10,000 \times g$ for $3 \mathrm{~min}$. After being resuspended twice with PBS buffer (137 mM NaCl, $2.7 \mathrm{mM} \mathrm{KCl,} 10 \mathrm{mM}$ $\left.\mathrm{Na}_{2} \mathrm{HPO}_{4}, 2 \mathrm{mM} \mathrm{KH} \mathrm{PO}_{4}, \mathrm{pH} 7.4\right), 200 \mu \mathrm{l}$ of bacterial suspension was transferred into a 96-well plate in which $\mathrm{OD}_{600}$ and fluorescence were read with excitation at $485 \mathrm{~nm}$ and emission at $528 \mathrm{~nm}$ using a Multi-Detection Microplate Reader, Synergy HT (BioTek). For each sample, three repetitions were performed with PBS buffer as a blank.

\section{Construction of counterselectable cassettes $\mathrm{nP}_{\text {Idh }}$-pheS* and plasmids $\mathrm{pG}^{+}-\mathrm{nP}$-pheS*}

To increase the expression of $\mathrm{PheS}^{*}$ protein, a series of counterselectable cassettes, namely $\mathrm{nP}_{\mathrm{ldh}}-p h e S^{*}$ were constructed as follows: the $\mathrm{P}_{1 \mathrm{dh}}$-pheS* cassette was PCR amplified using primer pair ldhF3 and pheSR2 from plasmid pleiss-P-pheS*. The resulting DNA fragment was digested with SalI and EcoRI and ligated into the corresponding sites of pUC19 to create plasmid pUC-P-pheS*. The promoter $\mathrm{P}_{1 \mathrm{lh}}$ was generated by PCR with primers ldhF3 and ldhR3, and the PCR product was digested with XhoI and SalI and inserted into the SalI site of pUC-P-pheS* to generate pUC-2P-pheS. The same procedure was carried out to construct the plasmid pUC$\mathrm{nP}$-pheS ( $\mathrm{n}$ : the copy number of $\mathrm{P}_{1 \mathrm{dh}}$ in the $\mathrm{nP}_{\mathrm{ldh}}-$ pheS* cassettes). To develop a counterselectable system in $L c$. lactis, the above plasmids pUC-nP-pheS* were digested with SalI and EcoRI, and the generating $\mathrm{nP}_{1 \mathrm{lh}}-p h e S^{*}$ cassettes (Fig. 4a) were ligated to the SalI and EcoRI sites of $\mathrm{pG}^{+}$host9 to yield plasmid $\mathrm{pG}^{+}$-nP-pheS*

\section{Functional analysis of the $\mathrm{pG}^{+}-\mathrm{nP}$-pheS* in Lc. lactis}

To knockout the $709 \mathrm{bp}$ fragment of the galactose operon in Lc. lactis NZ9000, $\mathrm{pG}^{+} \mathrm{UD}-\mathrm{nP}-\mathrm{pheS}^{*}$ was constructed 
as follows. Upstream with 1000 bp in size (amplified with primers upF and upR) and downstream with $1011 \mathrm{bp}$ (amplified with primers downF and downR) homology arms were PCR amplified from the genomic DNA of $L c$. lactis NZ9000 and spliced by an overlap extension PCR using primers upF and downR; Subsequently, the fused fragment was digested by KpnI and XhoI and inserted into the corresponding sites of the temperature-sensitive vectors $\mathrm{pG}^{+}$host9 [16] and $\mathrm{pG}^{+}-\mathrm{nP}^{\mathrm{p}} \mathrm{pheS}{ }^{*}$, resulting the plasmids $\mathrm{pG}^{+} \mathrm{UD}$ and $\mathrm{pG}^{+} \mathrm{UD}-\mathrm{nP}-\mathrm{pheS}$, respectively. The plasmid $\mathrm{pG}^{+} \mathrm{UD}$ and $\mathrm{pG}^{+} \mathrm{UD}-\mathrm{nP}$-pheS* were introduced into Lc. lactis NZ9000 to perform double-crossover homologous recombination as described previously [16]. Briefly, the recombinants were grown at $28^{\circ} \mathrm{C}$ until $\mathrm{OD}_{600} 0.8-1.0$, then transferred to $37^{\circ} \mathrm{C}$ for $2 \mathrm{~h}$ to allow the single-crossover integrants growth. Appropriate cultures were plated onto GM17 medium with $5 \mu \mathrm{g} / \mathrm{ml}$ erythromycin at $37{ }^{\circ} \mathrm{C}$. Subsequently, the single-crossover integrants were cultured in GM17 medium without erythromycin at $28{ }^{\circ} \mathrm{C}$ for excision of the vector by a second crossover process. The cultures were then plated onto GM9 plates containing $15 \mathrm{mM} p$-Cl-Phe at $37^{\circ} \mathrm{C}$. The single-crossover integrants and double-crossover mutants were both verified utilizing primer pair testF and testR.

To further confirm the function of $\mathrm{pG}^{+}-5 \mathrm{P}-\mathrm{pheS} *$, the ald $B$ gene encoding $\alpha$-acetolactate decarboxylase was knocked out from the Lc. lactis NZ9000 genome using the above protocols. Primer pairs of aldB-uF/aldB-uR and aldB-dF/aldB-dR were utilized for amplifying the upstream and downstream homology arms, and fused by an overlap extension PCR. The resultant $\sim 2.0 \mathrm{~kb}$ fragment was digested and inserted into the KpnI and XhoI sites of the vector $\mathrm{pG}^{+}-5 \mathrm{P}-\mathrm{pheS}^{*}$. Subsequently, the yielding $\mathrm{pG}^{+} \mathrm{UD} 2-5 \mathrm{P}-$ pheS* ${ }^{*}$ was transferred into $L c$. lactis NZ9000 to perform the double-crossover homologous recombination as described above. The mutant Lc. lactis $\mathrm{dA}$ was verified by PCR with the primer pair aldB-testF and aldB-testR, and the mutant genotype was also confirmed by sequence analysis (Biosune Company, Shanghai, China).

\section{Extending this counterselectable marker pheS* to other LAB}

To extend this counterselectable marker $p h e S^{*}$ to other LAB, L. casei was selected as a host. The mutant gene pheS* was generated as two fragments by an overlap extension PCR using the L. casei BL23 [36] genomic DNA as a template with the primers BL-pheSF and BL-siteR, BL-pheSR and BL-siteF, respectively. The point mutation responsible for $p$-Cl-Phe sensitivity was PCR amplified by the primer pair BL-siteF and BL-siteR annealing internal to pheS gene. The generated pheS* was digested with Pst $\mathrm{I}$ and $B g l \mathrm{II}$ and ligated to the compatible sites of pTRKH2 [37], creating pTRKH2-pheS*

To investigate the feasibility of the counterselectable marker pheS*, the plasmid pTRKH2-pheS* was introduced into L. casei BL23 by electroporation [13]. The recombinant $L$. casei BL23/pTRKH2-pheS* was incubated into MRS with $5 \mu \mathrm{g} / \mathrm{ml}$ erythromycin. Overnight cultures were streaked onto a GM9 plate containing $10 \mathrm{mM} p$-Cl-Phe, the cell survival was measured.

\section{Results \\ Bioinformatic analysis of PheS protein in selected LAB species}

Previously, it was reported that only a point mutant $p h e S^{*}$ gene encoding an A294G substitution in E. coli PheS [27] or an A312G substitution in Enterococcus faecalis PheS [32] resulted in the obviously sensitivity to the phenylalanine analog $p$-Cl-Phe. Hence, to identify the amino acid residue for site-directed mutagenesis, the amino acid sequences of PheS from Lc. lactis, L. casei, L. plantarum, $L$. brevis, L. rhamnosus and $S$. thermophilus were aligned with the amino acid sequences from E. coli and E. faecalis by Clustal X version 2.0 [30] and ESPript 3.0 [31]. As shown in Fig. 1, the amino acid residues A312 in Lc. lactis NZ9000, A312 in L. casei, A312 in L. plantarum, A312 in L. brevis, A312 in L. rhamnosus and A314 in S. thermophilus are strictly conserved compared to the residue A294 in E. coli [27] and A312 in E. faecalis [32], indicating that this alanine residue of PheS protein was highly conserved in LAB.

To verify the above putative result, we chose the amino acid residues A312 in Lc. lactis NZ9000 PheS for sitedirected mutagenesis. The pheS gene (accession number: NC_009004) encoding phenylalanyl-tRNA synthetase alpha subunit was identified from the genome of $L c$. lactis NZ9000. It was 1038 bp in size and composed of 345 amino acid residues. After precision mutation GCT to GGT by an overlap extension PCR strategy in codon 312 of the pheS gene, an A312G point mutation was introduced into the PheS protein, resulting a dominantnegative mutant protein $\mathrm{PheS}^{*}$. Moreover, we also tested the potential of A312G point mutation of PheS for counterselection in L. casei BL23.

\section{Functional analysis of the counterselectable marker $\mathrm{P}_{\text {Idh }}$-pheS* in Lc. lactis}

To test the feasibility of the gene $p h e S^{*}$ as a counterselectable marker in Lc. lactis, it was driven constitutively by a strong promoter of L-lactate dehydrogenase gene (ldh) in Lc. lactis NZ9000. Subsequently, this resultant $\mathrm{P}_{\mathrm{ldh}}$-pheS* cassette was inserted into the Lc. lactis/E. coli 


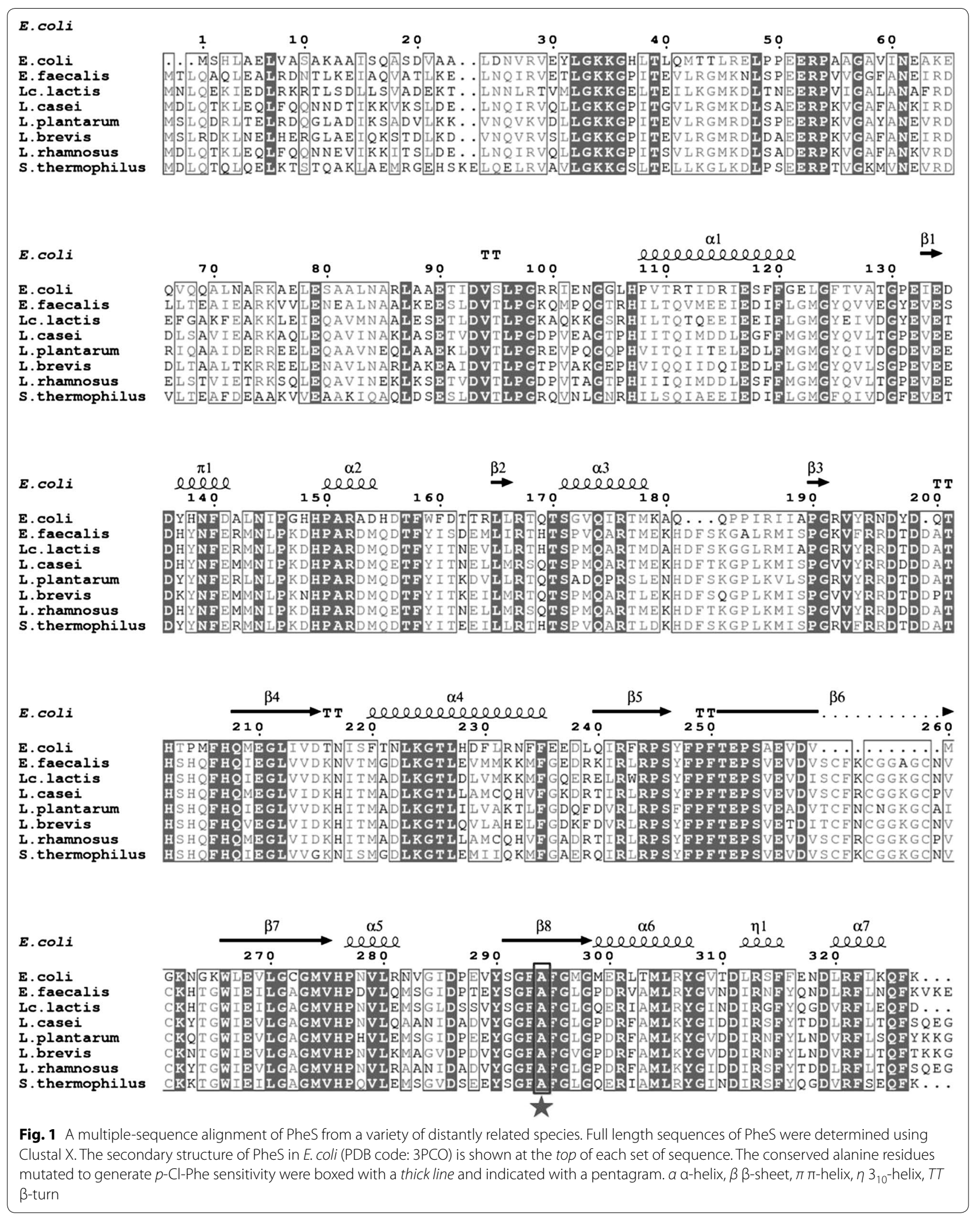


shuttle vector $\mathrm{pSec}$ :Leiss:Nuc, yielding the recombinant plasmid pleiss-P-pheS*. The schedule of construction of pleiss-P-pheS* was shown in Fig. 2.

After introduction of the plasmid pleiss-P-pheS* into Lc. lactis NZ9000, the sensitivity of the recombinant Lc. lactis NZ9000/pleiss-P-pheS* was measured on the GM9 plates containing $0,5,10,15 \mathrm{mM}$ phenylalanine analog $p$-Cl-Phe, respectively. As shown in Fig. 3, Lc. lactis NZ9000/pleiss-P-pheS* grew well on the GM9 plate without $p$-Cl-Phe, while the growth was completely inhibited in the presence of $15 \mathrm{mM}$ of $p$-Cl-Phe. But, unlike the Lc. lactis NZ9000/pleiss-P-pheS*, the growth of Lc. lactis NZ9000 equipped with the plasmid pSec:Leiss:Nuc as a control was not inhibited under the equivalent concentrations of $p$-Cl-Phe, indicating that the dominant-negative mutant protein $\mathrm{PheS}^{*}$ is functional as a stringent counterselectable marker in the presence of $15 \mathrm{mM}$ p-Cl-Phe.

\section{Creation of a counterselectable cassette $5 \mathrm{P}_{\mathrm{Idh}}$-pheS* in Lc. lactis}

The temperature sensitive plasmid $\mathrm{pG}^{+}$host 9 was widely used for gene(s) deletion and insertion in LAB. Here, a counterselectable system $\mathrm{PheS}^{*} / \mathrm{pG}^{+}$host9 was constructed based on a $\mathrm{pG}^{+}$host 9 carrying the fragment $\mathrm{P}_{\text {ldh }}$-pheS* from the plasmid pleiss-P-pheS*, and yielding $\mathrm{pG}^{+}$-P-pheS*. To investigate the feasibility of this vector for gene deletion, upstream and downstream homology arms of the $709 \mathrm{bp}$ fragment of galactose operon were spliced and inserted into $\mathrm{pG}^{+}$host9 and $\mathrm{pG}^{+}-\mathrm{P}-\mathrm{pheS}^{*}$, resulting $\mathrm{pG}^{+} \mathrm{UD}$ and $\mathrm{pG}^{+} \mathrm{UD}-\mathrm{P}-\mathrm{pheS}{ }^{*}$. The single-crossover integrants $L c$. lactis IG0 and Lc. lactis IG1 were both pipetted onto GM9 plates containing $15 \mathrm{mM} p$-Cl-Phe, respectively. Unfortunately, Lc. lactis IG1 was not completely inhibited by $p$-Cl-Phe. We supposed that this unexpected phenomenon might resulted from the low expression of PheS* protein from a chromosomal copy.

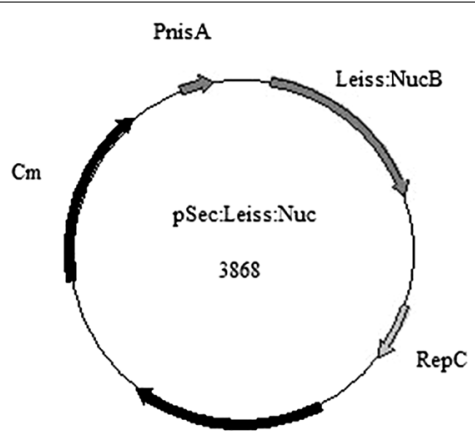

RepA

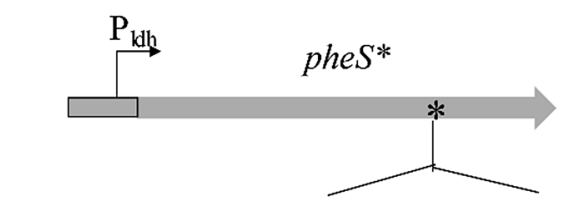

$p h e S^{*} 5$ '...........GTTTTGGTTTTGG $\ldots \ldots \ldots . .3$ '

pheS $\quad 5$ '.......... GTTTTGCTTTTGG .........3'

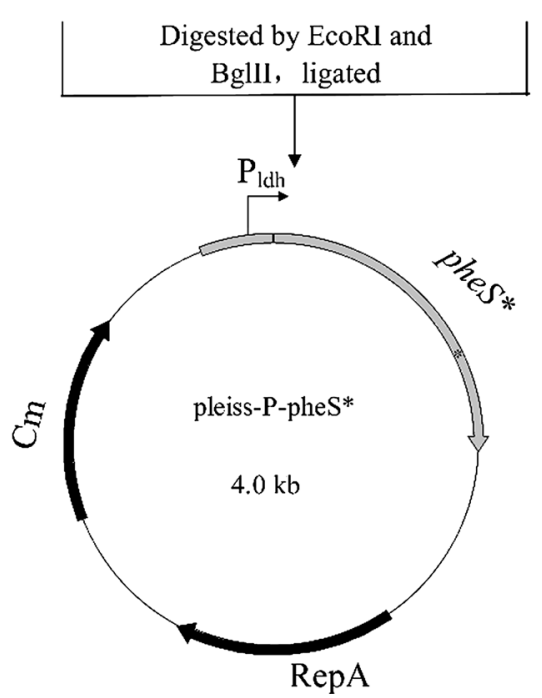

Fig. 2 Construction of a vector for detecting the PheS*/pG ${ }^{+}$host9 counterselectable system. The wild-type phes was changed to phe ${ }^{*}$ using an overlap extension PCR to introduce a point mutation of GCT to GGT. Pldh: the promoter region of the L-lactate dehydrogenase gene (Idh) (accession number: NC_017949) from LC. lactis NZ9000 


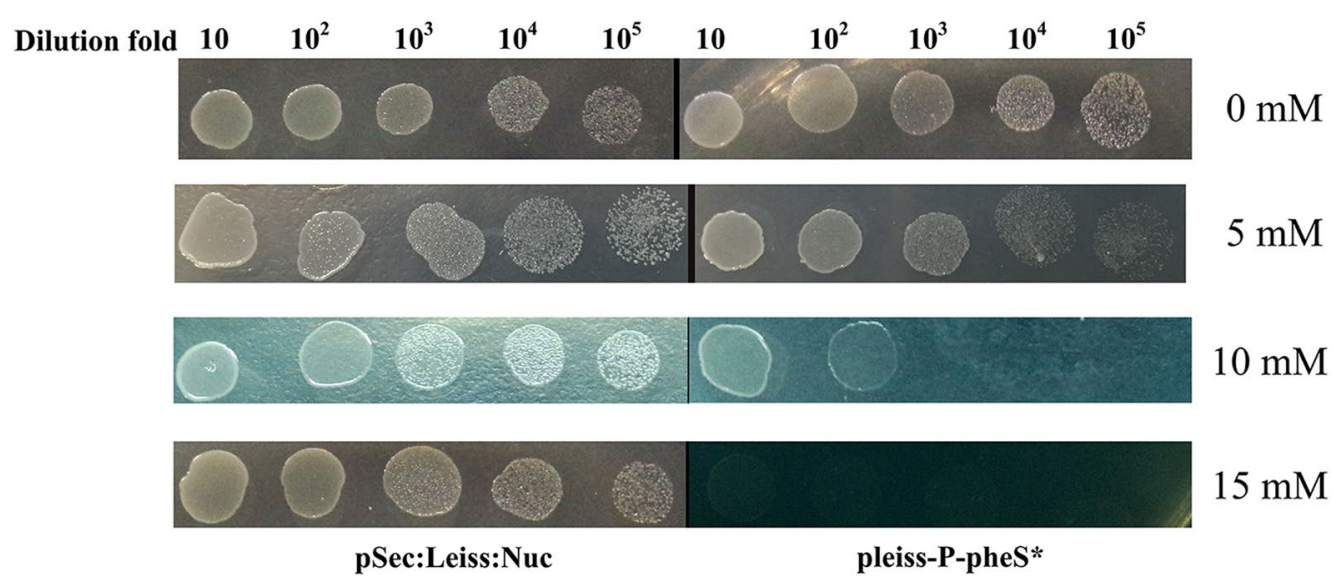

Fig. 3 Detection of the sensitivity of Lc. lactis NZ9000/pleiss-P-pheS* to p-Cl-Phe. Wild-type Lc. lactis NZ900 carrying either an empty vector (pSec:Leiss:Nuc) or a Lc. lactis derivative carrying the $\mathrm{P}_{\text {Idh }}$-phe $S^{*}$ cassette (pleiss-P-pheS*) were cultivated overnight in GM9 plates containing the indicated concentration of $p$-Cl-Phe. This experiment was performed in triplicate with the similar results

To increase the expression level of $p_{h e S} *$, we firstly tested whether cascading promoters could be functional in Lc. lactis. A series of plasmids pleiss-nP-gfp carrying promoter clusters $\mathrm{nP}_{1 \mathrm{lh}}-g f p$ were constructed and introduced into the Lc. lactis NZ9000. To optimize the constructed $\mathrm{nP}_{\mathrm{ldh}}-g f p$ promoter clusters, fluorescence intensity of each construct radiated from the green fluorescence protein after $12 \mathrm{~h}$ of aerobic incubation was determined. By analyzing the cell growth and relevant fluorescence of each recombinant strain, we found that the more copies of the $\mathrm{P}_{\text {ldh }}$ promoter were present in the expression cassette, the higher the specific fluorescence was (Fig. 4a). This result indicated that cascading promoters could improve the expression level of $g f p$ gene.

Subsequently, various copies of the $\mathrm{P}_{\text {ldh }}$ were driven the expression of dominant-negative mutant protein $\mathrm{PheS}^{*}$ (Fig. 4b). As shown in Fig. 4c, the increase of the $\mathrm{P}_{\text {ldh }}$ copies in the $\mathrm{nP}_{\text {ldh }}$-pheS ${ }^{*}$ cassettes inserted into the chromosomal locus of the integrants resulted in the enhanced sensitivity to $15 \mathrm{mM} p$-Cl-Phe. When the $p h e S^{*}$ gene expressed from five copies of the $\mathrm{P}_{\text {ldh }}$, the growth of $L c$. lactis IG5 was substantially inhibited. Thus, we chose the $5 \mathrm{P}_{\text {ldh }}$-pheS* cassette as a negative selectable marker for development of a counterselectable seamless mutagenesis system $\mathrm{PheS} / \mathrm{pG}^{+}$host9 in Lc. lactis.

\section{Functional analysis of the counterselectable system PheS*/ pG ${ }^{+}$host9 in Lc. lactis}

To verify the potential of the counterselectable system $\mathrm{PheS}^{*} / \mathrm{pG}^{+}$host9 in Lc. lactis NZ9000, a 709 bp fragment of the galactose operon was selected as a targeting region for deletion through the vector $\mathrm{pG}^{+} \mathrm{UD}-5 \mathrm{P}-\mathrm{pheS} \mathrm{S}^{*}$. After $p$-Cl-Phe counterselection, 24 resistance colonies picked randomly on a GM9 plate containing $15 \mathrm{mM} p$-Cl-Phe were all double-crossover occurred and 10 out of them (approximately 42\%) were shown to possess the expected mutant genotype by PCR determination and sequencing. The result was closed to the theoretical value (50\%) since the target region of the galactose operon was not essential for the growth of Lc. lactis NZ9000 (Fig. 5a, b). Hence, we supposed that the $5 \mathrm{P}_{\text {ldh }}$-pheS* cassette based counterselectable system was functional in Lc. lactis NZ9000 to perform seamless gene deletion.

To further determine whether the counterselectable system $\mathrm{PheS}^{*} / \mathrm{pG}^{+}$host 9 would be feasible for genome engineering, ald $B$ gene which encodes for $\alpha$-acetolactate decarboxylase catalyzing $\alpha$-acetolactate to acetoin in the diacetyl biosynthesis in Lc. lactis was deleted by this system (Fig. 5a). Twenty-one colonies were selected randomly and detected by PCR amplification. The doublecrossover events also occurred in $100 \%$, and six out of them were the expected mutants (Fig. 6). This result indicated that the efficiency of screening double-crossover mutants was significantly improved compared with using $\mathrm{pG}^{+}$host9 alone in our laboratory previously [18].

\section{Potential of the counterselectable marker pheS* in other LAB}

To test the feasibility of the gene $p h e S^{*}$ as a counterselection marker in other LAB, the strain L. casei BL23 was selected as a host. After insertion of pheS* into pTRKH2 [37], the obtained plasmid pTRKH2-pheS* was introduced into $L$. casei BL23. Subsequently the sensitivity of the recombinant $L$. casei BL23/pTRKH2-pheS* to $p$-ClPhe was measured on the GM9 plates containing $10 \mathrm{mM}$ $p$-Cl-Phe. As shown in Fig. 7, the recombinant L. case $i$ BL23/pTRKH2 grew well on the GM9 plate containing $10 \mathrm{mM} p$-Cl-Phe, while the growth of $L$. casei BL23/ 


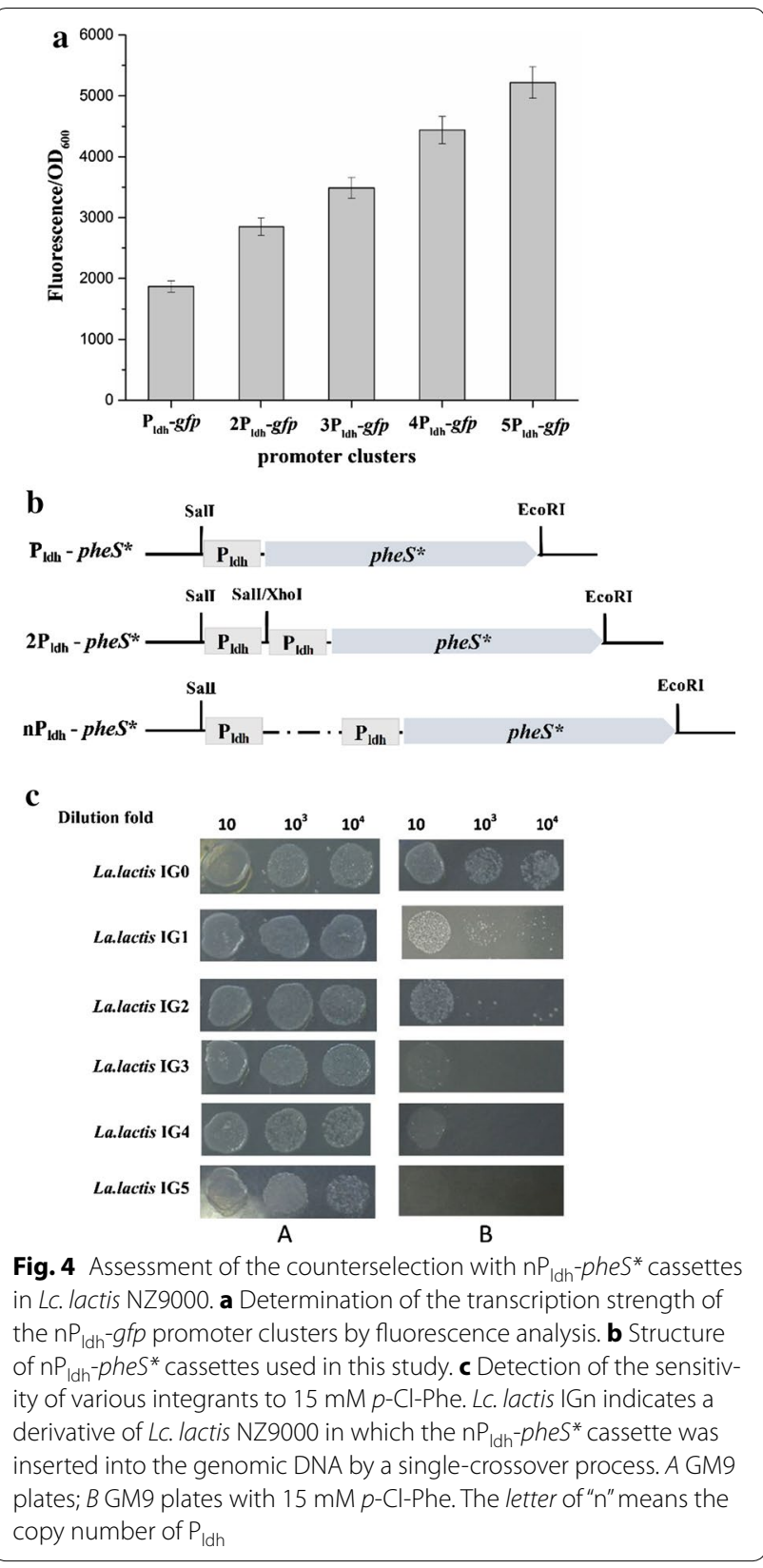

pTRKH2-pheS* was obviously inhibited, indicating that the conditional-lethal mutant gene $p h e S^{*}$ has the potential as a counterselectable marker in $L$. casei and other LAB.

\section{Discussion}

In consideration of the increasing use in industrial and medical area, LAB are intensively studied on their genetics and metabolism $[9,10]$. Therefore, efficient genome engineering tools are necessary for target gene(s) deletion or insertion for functional analysis or rerouting the metabolic flux [38]. In this study, a seamless negative selectable mutagenesis system $\mathrm{PheS} / \mathrm{pG}^{+}$host9 was developed. We also demonstrated its feasibility by constructing strains bearing the targeting seamless deletion of a $709 \mathrm{bp}$ fragment in lactococcal galactose operon and ald $B$ gene. Expectedly, the ratio of the double-crossover event was $100 \%$ after counterselection by $p$-Cl-Phe.

To our knowledge, this is the first report that the mutated pheS allele can be used as a counterselection marker for efficient and rapid genomic engineering in Lc. lactis. Previously, the development of a pheS based counterselection system in Streptococcus mutans, which is a close relative to Lc. lactis, has been reported [28]. However, S. mutans is a pathogenic bacterium distributed in the dental caries and could not be applied in the food field and used as a cell factory [39]. We expected that combining the counterselectable marker $p h e S^{*}$ with the traditional genetic tool $\mathrm{pG}^{+}$host9 [16] would overcome the bottleneck of laboriously screening of the double-crossover recombinants, and this system has greatly potential in genome engineering in LAB.

Protein sequence analysis suggested that the alanine residue of PheS protein is highly conserved in LAB (Fig. 1). Here we have demonstrated the feasibility of pheS* as a counterselectable marker in Lc. lactic and $L$. casei, these results were consistent with the previously results in S. mutans and Enterococcus faecalis [28, 32]. Therefore, we speculated that the dominant-negative mutant gene $p h e S^{*}$ might be widely used as a counterselectable marker in a variety of lactic acid bacterial species. However, the sensitivity of the cells to $p$-Cl-Phe was depended on strain specific manner, such as $15 \mathrm{mM}$ $p$-Cl-Phe for Lc. lactis NZ9000, $20 \mathrm{mM} p$-Cl-Phe for $S$. mutans [28]. Hence, optimization of the PheS* expression is needed when employing pheS* $^{*}$ as a counterselectable marker in other LAB strains [25, 28].

In this study, the $\mathrm{PheS}^{*}$ protein under the control of a promoter $\mathrm{P}_{\text {ldh }}$ has the ability of completely inhibiting the growth of Lc. lactis NZ9000 at $15 \mathrm{mM} p$-Cl-Phe, suggesting it is possible to use $\mathrm{P}_{\mathrm{ldh}}$-pheS*cassette as a counterselectable marker in Lc. lactis. However, the growth of the recombinants with $\mathrm{P}_{\text {ldh }}$-pheS* inserted into the chromosomal locus was not completely inhibited by even higher concentration of $p$-Cl-Phe. This unexpected result means that the ratio of screening double-crossover recombinants would not be $100 \%$ after $p$-Cl-Phe counterselection. We speculated that this phenomenon was caused by low expression level of PheS* [28], because the copy number of $\mathrm{P}_{\text {ldh }}$-pheS* from the chromosomal locus was lower than that in the plasmid pleiss-P-pheS*. Lower yield of PheS" was insufficient to compete with the background expression of wild-type PheS to form complexes with phenylalanyl-tRNA synthetase beta subunit (PheT) 
a
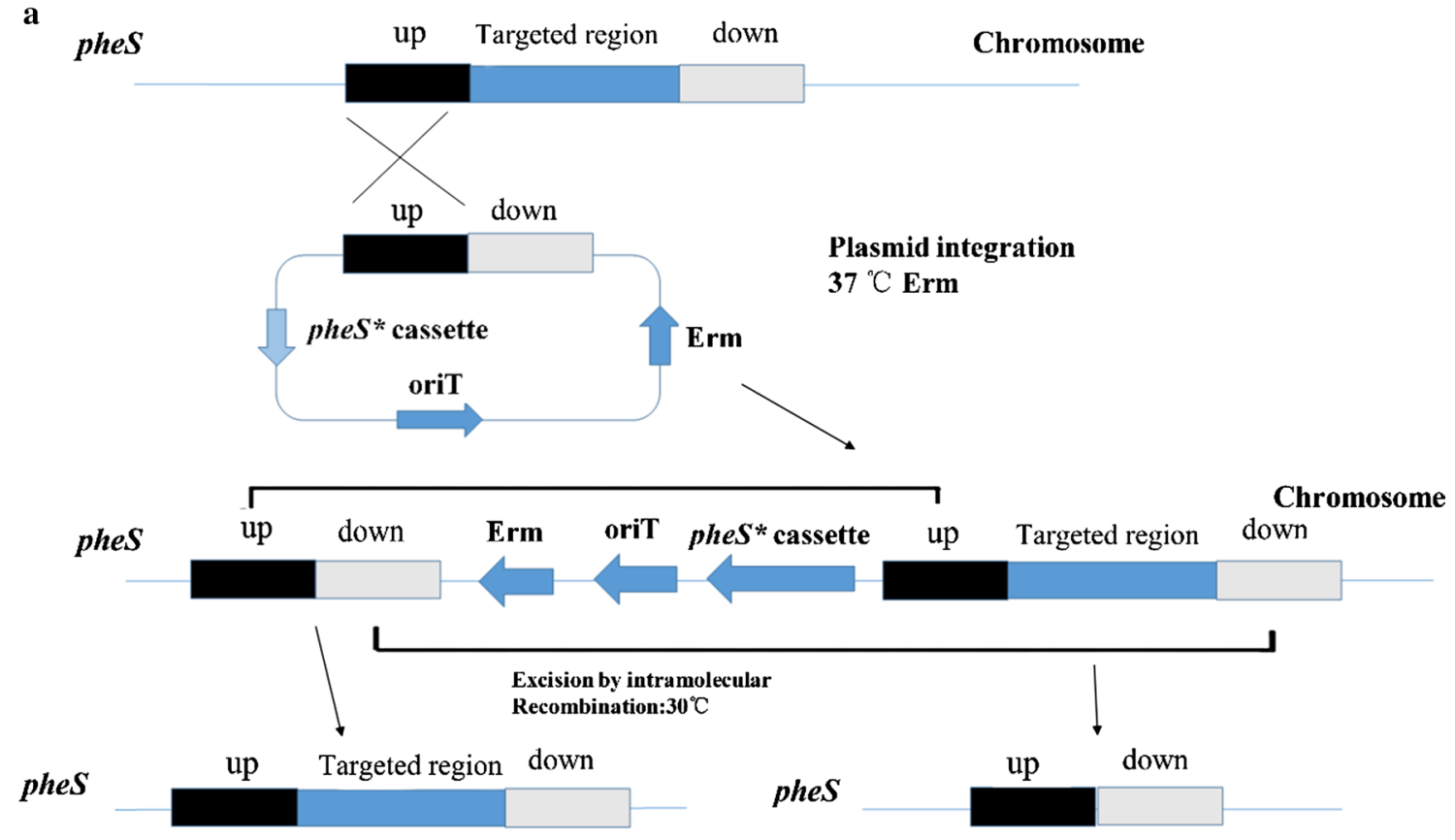

Wild type

Deletion mutant

b

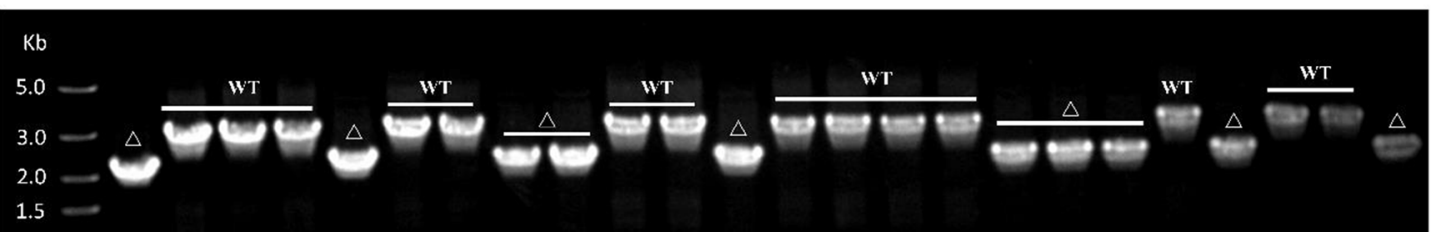

Fig. 5 Construction of the PheS*/pG ${ }^{+}$host9 counterselectable system in Lc. lactis NZ9000. a An effcient counterselectable system PheS*/pG ${ }^{+}$host9 used to create gene deletions in Lc. lactis NZ9000. The "pheS* cassette" indicates the pheS* gene under the control of five cascading P Pld. "up" and "down" indicate the upstream and downstream homology arms of the targeted region. "Erm" indicates the erythromycin resistant gene. "OriT" indicates the temperature sensitive origin of replication. $\mathbf{b}$ Twenty-four $p$-Cl-Phe-resistant colonies were amplified by PCR to screen for the deletion of $709 \mathrm{bp}$ fragment of the galactose operon. The expected PCR fragment from the mutant type $(\Delta)$ is approximately $2.0 \mathrm{~kb}$, while the band from the wild-type (WT) is about $2.7 \mathrm{~kb}$

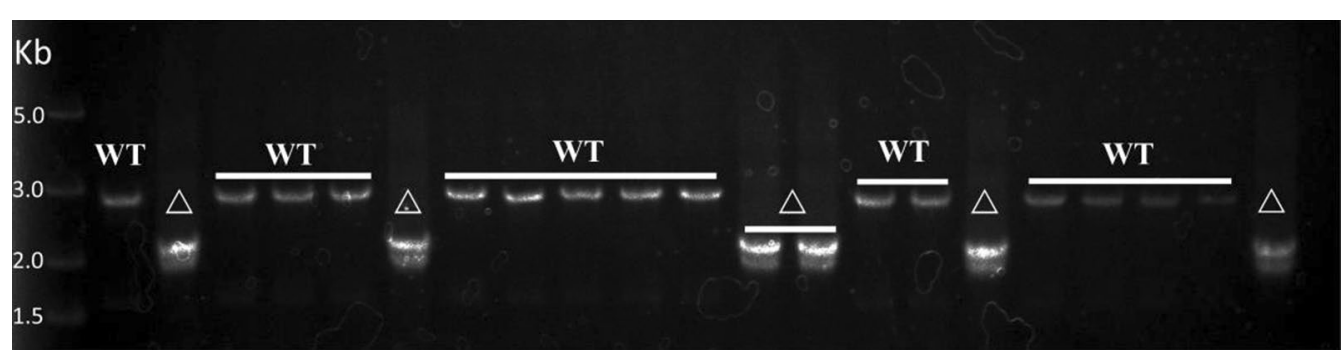

Fig. 6 Generation of a seamless in-frame aldB deletion mutant. Twenty-one $p$-Cl-Phe-resistant colonies were amplified by PCR to screen for the deletion of the aldB gene $(711 \mathrm{bp})$. The expected PCR fragment from the mutant type $(\Delta)$ is approximately $2.0 \mathrm{~kb}$, while the band from the wild-type (WT) is about $2.7 \mathrm{~kb}$ 


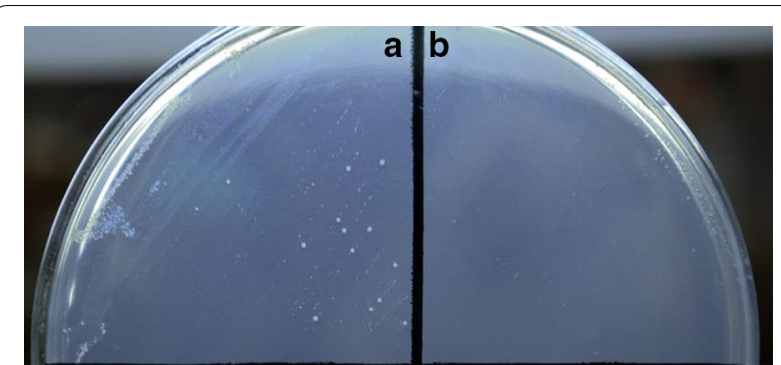

Fig. 7 -Cl-Phe sensitivity of L. casei strains. Wild-type L. casei BL23 carrying an empty shuttle vector (a) or a derivative carrying the pheS* (b) were cultivated overnight in GM9 plates containing $10 \mathrm{mM} \mathrm{p}$-ClPhe at $37^{\circ} \mathrm{C}$

[40]. In these cases, a strategy of cascading promoters [41] was employed to improve the expression level of protein $\mathrm{PheS}^{*}$. Surprisingly, when protein $\mathrm{PheS}^{*}$ was driven simultaneously by five copies of the $P_{\text {ldh }}$, the generating integrant $L c$. lactis IG5 was substantially inhibited in the presence of $15 \mathrm{mM} p$-Cl-Phe and the ratio of screening double-crossover recombinants was $100 \%$, suggesting recombination among the promoters was not occurred and the use of repeated $\mathrm{P}_{\text {ldh }}$ promoters could not confer genetic instability [41]. This strategy provides a new idea to address the issue of the low expression of the exogenous protein(s) in LAB.

Several strategies have been employed to fulfill the genome engineering in LAB by homologous doublecrossover using a solely conditional replication plasmid [38] or combining with other counterselectable system, such as upp [22] or oroP [24] based cassettes. Compared with those methods, the negative selectable system $\mathrm{PheS}^{*} / \mathrm{pG}^{+}$host9 has several advantages. (1) It greatly simplifies the procedure for screening doublecrossover recombinants. For example, taking only 2 days to screen double-crossover variants after the singlecrossover integrants were subcultured at $28{ }^{\circ} \mathrm{C}$. The ratio of the double-crossover recombinants was $100 \%$ after $p$-Cl-Phe counterselection. However, the ratio between the deletion and wild-type strains may not be the theoretical value (1:1), it can vary considerably depending on the function of gene(s) to be deleted. (2) To our knowledge, among all the reported counterselectable markers, only $p h e S^{*}$ has the greatly potential to be widely utilized in wild-type $\mathrm{LAB}$ without pretreatment. In contrast to other counterselectable system, the variants required the counterselectable marker deficient strains, as in the case of upp [21-23] and oroP [24]. Recently, a new counterselection method for wild-type $L c$. lactis genome engineering based on class IIa bacteriocin sensitivity was reported [42]. However, the li006Dlitation of this method to be widely used in LAB was the sensitivity to bacteriocins which would depend on the interaction between the listerial MpnC and the native PtnD [42]. (3) Strains without pheS* can naturally grow on GM9 medium with $15 \mathrm{mM}$ $p$-Cl-Phe. This means $15 \mathrm{mM} p$-Cl-Phe has no side-effect on the growth of the expected mutants.

Moreover, this mutagenesis system $\mathrm{PheS}^{*} / \mathrm{pG}^{+}$host9 allowed gene deletion without any genomic scarring [15] in Lc. lactis, as the case of the aldB gene. The generating genetically modified microorganisms (GMOs) [14] were seamless mutagenesis which means only leaving self-DNA in its native genome location [15]. Therefore, this system is useful in seamless gene deletions in industrial strains. However, this seamless mutagenesis system $\mathrm{PheS}^{*} / \mathrm{pG}^{+}$host 9 remains challenging in large DNA fragment deletions or insertions. In this study, the limited length of the targeted DNA fragment was mostly from the low efficient homologous recombination mediated by RecA [17]. In consideration of the ratio of the double-crossover recombinants was $100 \%$ after $p$-Cl-Phe counterselection, the ideal goal for deletion or insertion of large DNA fragment is the new genome engineering tools responsible for targeted fragments replacement by selection and the $5 \mathrm{P}_{\text {ldh }}$-pheS ${ }^{*}$ cassette responsible for selectable marker excision by counterselection [15].

\section{Conclusions}

A seamless mutagenesis system $\mathrm{PheS}^{*} / \mathrm{pG}^{+}$host9 based on a counterselectable marker $p h e S^{*}$ and a temperature sensitive plasmid $\mathrm{pG}^{+}$host 9 was developed in Lc. lactis. Moreover, this system can be used for rapidly constructing a seamless mutagenesis (deleted or inserted) strain. We also extended the counterselectable marker pheS* to $L$. casei. Although the feasibility of $p h e S^{*}$ as a counterselectable marker used in other $\mathrm{LAB}$ remains to be demonstrated, we speculated that this conterselectable marker will accelerate the analysis of genes with unknown function and metabolic engineering research in LAB.

\section{Abbreviations}

LAB: lactic acid bacteria; phes: gene of phenylalanyl-tRNA synthetase alpha subunit; pheS*: the mutant pheS gene; PheS*: phenylalanyl-tRNA syn-

thetase alpha subunit with an $A 312 G$ substitution; $P_{\text {ldh }}$ : promoter of the $L C$. lactis NZ9000 L-lactate dehydrogenase; $p$-Cl-Phe: $p$-chloro-phenylalanine; SSDR: single-stranded DNA recombineering; DSDR: double-stranded DNA recombineering.

\section{Authors' contributions}

YPX, TTG and JK conceived and designed the experiments, YPX carried out the experimental work. YPX, TTG, YLM and JK wrote and revised the manuscript. All authors read and approved the final manuscript.

\section{Acknowledgements}

We thank N. Galleron for kindly providing the plasmid pSec:leiss:Nuc and LC. lactis NZ9000. We also thank I. Biswas and E. Maguin for their generous gift of the plasmid $\mathrm{pG}^{+}$host9. 


\section{Competing interests}

The authors declare that they have no competing interests.

\section{Availability of data and materials}

The datasets supporting the conclusions of this article are included within the article.

\section{Funding}

This work was supported by the National Natural Science Foundation of China (Grants 31400077 and 31471715) and the Public Service Sectors (Agriculture) Special and Scientific Research Projects Hi-Tech Research and Development Program of China (Grant 201503134).

\section{Publisher's Note}

Springer Nature remains neutral with regard to jurisdictional claims in published maps and institutional affiliations.

Received: 27 April 2017 Accepted: 28 June 2017

Published online: 05 July 2017

\section{References}

1. Cavanagh D, Fitzgerald GF, McAuliffe O. From field to fermentation: the origins of Lactococcus lactis and its domestication to the dairy environment. Food Microbiol. 2015:47:45-61.

2. Leroy F, De Vuyst L. Lactic acid bacteria as functional starter cultures for the food fermentation industry. Trends Food Sci Technol. 2004;1 5:67-78.

3. Kleerebezem M, Hugenholtz J. Metabolic pathway engineering in lactic acid bacteria. Curr Opin Biotech. 2003;14:232-7.

4. Liu J, Dantoft SH, Wurtz A, Jensen PR, Solem C. A novel cell factory for efficient production of ethanol from dairy waste. Biotechnol Biofuels. 2016;9:33.

5. Guimaraes VD, Innocentin S, Lefevre F, Azevedo V, Wal JM, Langella P, Chatel JM. Use of native lactococci as vehicles for delivery of DNA into mammalian epithelial cells. Appl Environ Microbiol. 2006;72:7091-7.

6. Kruger C, Hu Y, Pan Q, Marcotte H, Hultberg A, Delwar D, van Dalen PJ, Pouwels PH, Leer RJ, Kelly CG, et al. In situ delivery of passive immunity by lactobacilli producing single-chain antibodies. Nat Biotechnol. 2002:20:702-6.

7. Steidler L, Hans W, Schotte L, Neirynck S, Obermeier F, Falk W, Fiers W, Remaut E. Treatment of murine colitis by Lactococcus lactis secreting interleukin-10. Science. 2000;289:1352-5.

8. Wyszynska A, Kobierecka P, Bardowski J, Jagusztyn-Krynicka EK. Lactic acid bacteria-20 years exploring their potential as live vectors for mucosal vaccination. Appl Microbiol Biotechnol. 2015:99:2967-77.

9. Rossi M, Amaretti A, Raimondi S. Folate production by probiotic bacteria Nutrients. 2011:3:118-34

10. Thakur K, Tomar SK, De S. Lactic acid bacteria as a cell factory for riboflavin production. Microb Biotechnol. 2016;9:441-51.

11. van Pijkeren JP, Britton RA. High efficiency recombineering in lactic acid bacteria. Nucleic Acids Res. 2012;40:e76.

12. Oh JH, van Pijkeren JP. CRISPR-Cas9-assisted recombineering in Lactobacillus reuteri. Nucleic Acids Res. 2014;42:e131.

13. Yang P, Wang J, Qi Q. Prophage recombinases-mediated genome engineering in Lactobacillus plantarum. Microb Cell Fact. 2015;14:154.

14. van Pijkeren JP, Britton RA. Precision genome engineering in lactic acid bacteria. Microb Cell Fact. 2014;13(Suppl 1):S10.

15. Wang $H$, Bian $X$, Xia L, Ding X, Muller R, Zhang Y, Fu J, Stewart AF. Improved seamless mutagenesis by recombineering using $c c d B$ for counterselection. Nucleic Acids Res. 2014;42:e37.

16. Maguin E, Duwat P, Hege T, Ehrlich D, Gruss A. New thermosensitive plasmid for gram-positive bacteria. J Bacteriol. 1992;174:5633-8.

17. Biswas I, Gruss A, Ehrlich SD, Maguin E. High-efficiency gene inactivation and replacement system for gram-positive bacteria. J Bacteriol. 1993:175:3628-35.

18. Guo T, Kong J, Zhang L, Zhang C, Hu S. Fine tuning of the lactate and diacetyl production through promoter engineering in Lactococcus lactis. PLOS ONE. 2012;7:e36296.
19. Lu W, Kong J, Kong W. Construction and application of a foodgrade expression system for Lactococcus lactis. Mol Biotechnol. 2013;54:170-6.

20. Wang T, Lu W, Lu S, Kong J. Protective role of glutathione against oxidative stress in Streptococcus thermophilus. Int Dairy J. 2015;45:41-7.

21. Goh YJ, Azcarate-Peril MA, O'Flaherty S, Durmaz E, Valence F, Jardin J, Lortal S, Klaenhammer TR. Development and application of a upp-based counterselective gene replacement system for the study of the S-layer protein SlpX of Lactobacillus acidophilus NCFM. Appl Environ Microbiol. 2009;75:3093-105.

22. Martinussen J, Hammer K. Cloning and characterization of upp, a gene encoding uracil phosphoribosyltransferase from Lactococcus lactis. J Bacteriol. 1994;176:6457-63.

23. Martinussen J, Hammer K. Powerful methods to establish chromosomal markers in Lactococcus lactis: an analysis of pyrimidine salvage pathway mutants obtained by positive selections. Microbiology. 1995;141(Pt 8):1883-90

24. Solem C, Defoor E, Jensen PR, Martinussen J. Plasmid pCS1966, a new selection/counterselection tool for lactic acid bacterium strain construction based on the oroP gene, encoding an orotate transporter from Lactococcus lactis. Appl Environ Microbiol. 2008;74:4772-5.

25. Carr JF, Danziger ME, Huang AL, Dahlberg AE, Gregory ST. Engineering the genome of Thermus thermophilus using a counterselectable marker. J Bacteriol. 2015;197:1135-44.

26. Kino Y, Nakayama-Imaohji H, Fujita M, Tada A, Yoneda S, Murakami K, Hashimoto M, Hayashi T, Okazaki K, Kuwahara T. Counterselection employing mutated phes for markerless genetic deletion in Bacteroides species. Anaerobe. 2016;42:81-8.

27. Kast $\mathrm{P}$, Hennecke $H$. Amino acid substrate specificity of Escherichia coli phenylalanyl-tRNA synthetase altered by distinct mutations. J Mol Biol. 1991;222:99-124.

28. Xie Z, Okinaga T, Qi F, Zhang Z, Merritt J. Cloning-independent and counterselectable markerless mutagenesis system in Streptococcus mutans. Appl Environ Microbiol. 2011;77:8025-33.

29. Chu LL, Pandey RP, Jung N, Jung HJ, Kim EH, Sohng JK. Hydroxylation of diverse flavonoids by CYP450 BM3 variants: biosynthesis of eriodictyol from naringenin in whole cells and its biological activities. Microb Cell Fact. 2016:15:135.

30. Larkin MA, Blackshields G, Brown NP, Chenna R, McGettigan PA, McWilliam H, Valentin F, Wallace IM, Wilm A, Lopez R, et al. Clustal W and Clustal $X$ version 2.0. Bioinformatics. 2007;23:2947-8.

31. Robert X, Gouet P. Deciphering key features in protein structures with the new ENDscript server. Nucleic Acids Res. 2014;42:W320-4.

32. Kristich CJ, Chandler JR, Dunny GM. Development of a host-genotypeindependent counterselectable marker and a high-frequency conjugative delivery system and their use in genetic analysis of Enterococcus faecalis. Plasmid. 2007:57:131-44.

33. Kuipers OP, de Ruyter PGGA, Kleerebezem M, de Vos WM. Quorum sensing-controlled gene expression in lactic acid bacteria. J Biotechnol. 1998;64:15-21.

34. Le Loir Y, Gruss A, Ehrlich SD, Langella P. A nine-residue synthetic propeptide enhances secretion efficiency of heterologous proteins in Lactococcus lactis. J Bacteriol. 1998:180:1895-903.

35. Holo H, Nes IF. High-frequency transformation, by electroporation, of Lactococcus lactis subsp. cremoris grown with glycine in osmotically stabilized media. Appl Environ Microbiol. 1989;55:3119-23.

36. Hazebrouck S, Pothelune L, Azevedo V, Corthier G, Wal JM, Langella P. Efficient production and secretion of bovine beta-lactoglobulin by Lactobacillus casei. Microb Cell Fact. 2007:6:12

37. O'Sullivan DJ, Klaenhammer TR. High- and low-copy-number Lactococcus shuttle cloning vectors with features for clone screening. Gene. 1993:137:227-31.

38. Fang F, O'Toole PW. Genetic tools for investigating the biology of commensal lactobacilli. Front Biosci (Landmark Ed). 2009:14:3111-27.

39. Legenova K, Bujdakova H. The role of Streptococcus mutans in the oral biofilm. Epidemiol Mikrobiol Imunol. 2015:64:179-87.

40. Mermershtain I, Finarov I, Klipcan L, Kessler N, Rozenberg H, Safro MG. Idiosyncrasy and identity in the prokaryotic Phe-system: crystal structure of E. coli phenylalanyl-tRNA synthetase complexed with phenylalanine and AMP. Protein Sci. 2011;20:160-7. 
41. Li M, Wang J, Geng Y, Li Y, Wang Q, Liang Q, Qi Q. A strategy of gene overexpression based on tandem repetitive promoters in Escherichia coli. Microb Cell Fact. 2012;1:19.
42. Wan X, Usvalampi AM, Saris PE, Takala TM. A counterselection method for Lactococcus lactis genome editing based on class lla bacteriocin sensitivity. Appl Microbiol Biotechnol. 2016;100:9661-9.
Submit your next manuscript to BioMed Central and we will help you at every step:

- We accept pre-submission inquiries

- Our selector tool helps you to find the most relevant journal

- We provide round the clock customer support

- Convenient online submission

- Thorough peer review

- Inclusion in PubMed and all major indexing services

- Maximum visibility for your research

Submit your manuscript at www.biomedcentral.com/submit
(O) Biomed Central 